\title{
E-Collaboration among Students of Two Regions: Impacts on English Language Learning through Peer Learning
}

\author{
Mimi Nahariah Azwani binti Mohamed \\ Nurizah binti Md. Ngadiran \\ Nurzarina binti Abdul Samad \\ Nor Fadhilah binti Ahmad Powzi \\ Centre for Language Studies \\ Universiti Tun Hussein Onn Malaysia \\ Batu Pahat, Johor, Malaysia
}

\begin{abstract}
Over the years, e-collaborative learning is increasingly acknowledged among educators in higher learning institutions. Apart from holding the potential to promote innovative learning experience in language teaching and learning, this teaching technique also provides opportunities for language learners to improve their global intercultural communication. This study is part of a larger study which examines the impact of e-collaborative learning on second and foreign language learners. The e-collaborative learning was conducted between 10 students of one university in Malaysia and 10 students of one university in France. These students communicated with each other through Skype, WhatsApp and Google document to produce a video project. This paper presents the finding on students' perceptions of ecollaborative learning from the perspective of the Malaysian students. The data were collected through semi-structured interviews and analysed using thematic analysis. The finding shows that e-collaborative learning between second and foreign language learners of two regions encourages positive language learning, reduces language anxiety and increases the confidence level in using the language.
\end{abstract}

Keywords: collaborative learning, intercultural communication, peer language learning.

\section{Introduction}

The global job market demands for a future workforce who can demonstrate exceptional employability skills at a global level. The employability skills sought after by today's employers include the 4Cs; communication, collaboration, creative thinking, problem-solving, and critical thinking skills (Wolff \& Booth, 2017). Hence, higher education institutions all over the world hold great 
responsibilities in developing graduates with these global skills. It is believed that the development of these $4 \mathrm{Cs}$ can be achieved through e-collaborative teaching and learning in the classroom.

Collaborative teaching and learning has a great impact on students' learning process as it promotes working in groups, negotiating and making decisions (Daniels \& Walker, 2001). The concept of collaborative learning is in line with Vygotsky's Zone of Proximal Development (ZPD) that represents the concept of learning with the support of a teacher or peers (Vygotsky, 1978). The interactions that occur between the learners and the teacher or peers can facilitate the cognitive growth and knowledge acquisition of the learners. However, collaboration and interactions among peers and teachers within a classroom alone may not be sufficient to develop the required global skills.

In the context of English as a second language (ESL), collaborative learning can be seen as an approach that can develop the required 4Cs, as well as the English language proficiency. By organising collaborative language teaching and learning, students have the opportunity to interact with one another and that can boost their English language proficiency level and communication skills.

In the current era of technology advancement, the need for language teaching and learning to extend beyond the classroom walls is much needed to facilitate better learning (Choi \& Nunan, 2018; Richards, 2015). This suggests that collaborative learning needs to evolve to e-collaborative learning. Within this context, learning can occur online whereby students can gain access to an abundance of information online and would not be dependent on the teachers. Apart from that, students would have the convenience of learning with their peers without having to attend classes.

With the use of technologies, learners hold more responsibility for their learning where they can tailor learning according to their preferences (Froyd \& Simpson, 2008). As such, e-collaborative teaching and learning can be seen as an approach that encourages students to be independent and autonomous learners. Learners who are autonomous and independent are more likely to be more successful than learners who do not process the information from their learning (Richards, 2015).

Through e-collaborative teaching and learning, the collaboration among peers and teachers is done online. Besides that, students have the opportunity to learn from fellow students from other universities as well as from other countries. The availability of Skype, Zoom and many other online platforms make it possible for teachers and students to engage in e-collaborative teaching and learning, locally and globally. The teachers play the role as facilitators where they structure and delegate tasks to students, as well as support and observe the learning process and students' progression (Okomoto, 2003).

This paper is part of a larger research examining e-collaborative second/foreign language learning between two groups of students in distant locations, Malaysia 
and France. This paper focuses on students' experience and perceptions of ecollaborative language learning, particularly learners of English as a foreign language. It is hoped that the findings could shed lights on the impacts of ecollaborative teaching and learning on second or foreign language learning.

\section{Literature Review}

Studies on collaborative learning have illustrated that this approach encourages interactions and facilitates language learning (Angelova \& Zhao, 2016; Tanghe \& Park, 2016). For instance, Angelova and Zhao (2016) conducted a study on collaborative learning between native and non-native English language learners of two regions, America and China. In this study, twenty-three American students from an ESL teaching programme tutored twenty-six Chinese first-year English-majors on their grammar structures. They communicated through a discussion board, email and Skype. The results showed that the American students improved their teaching skills through tutoring non-native speakers of English and the Chinese students improved their language skills. In the context of language learning, the American students who controlled the knowledge about the language played the role as the mentors while the Chinese students depended on the American students for the knowledge.

Apart from facilitating language learning, e-collaborative learning could also provide opportunities for intercultural communication. In their study, Tanghe and Park (2016) examined the implementation of an international collaboration project, involving two participants in South Korea and two participants in the United States. The four participants were graduates of language teacher education. The data obtained for this study were from the participants' written reflections, individual interviews, e-mail messages, course blogs, and teachers' observation reflection journals. The findings showed that international collaboration enhanced the participants' intercultural competences. As the participants in this study were graduates who learnt the language for teaching, a study is needed to investigate in what ways e-collaborative learning could enhance second or foreign language learners' language skills and intercultural competencies.

Both the studies by Angelova and Zhao (2016) and Tanghe and Park (2016) investigated e-collaborative learning where the native speakers facilitated the non-native speakers of English, highlighting the concept of peer mentoring. While it may have its strengths, peer mentoring may not always be successful. Kissau and King (2014) investigated the benefits of a partnership between 27 mentors and 27 mentees. The results showed that the partnership was beneficial and successful when both parties shared expertise in the content area and worked together in producing given tasks. This suggests that the partnership may not be successful or effective when only one party is the provider of the expertise while the other is the recipient. In peer mentoring, although mentors are the facilitators, they also need to gain benefits from the mentoring process. This raises the issue of mutual benefits where both members of a partnership should provide expertise and receive learning benefits. 
The studies above highlight the need for e-collaborative learning between students of different regions to provide a meaningful language learning environment and enhance intercultural competencies. In addition, there is a need for these students to have similar levels of expertise in the language. As such, a study that involves non-native speakers of English of different regions would provide insights on e-collaborative learning from the perspective of second or foreign language learners.

\section{Methodology}

\subsection{The Study Site and Participants}

This project was conducted to examine the impacts of online intercultural collaborations on students' language learning. It involved one institution in France and one institution in Malaysia. There were eleven French students enrolled in the Intercultural Communication Course in France. As such, eleven Malaysian students from one English course were recruited to match this number. The selection of the Malaysian students was made through nonprobability sampling method where these students were recruited on a voluntary basis. Both groups of students were non-native speakers of English. The Malaysian students were in their second year, attending an English course while the French students were in their third year. Each Malaysian student was paired up with a French partner and a total of 11 pairs were formed. Their mean of communication was mainly online and the platforms used for online communication were WhatsApp, Skype and Google document. There was a time difference of seven hours with Malaysia being ahead of France.

\subsection{The Design of the Project}

The two instructors who conducted this project, one from Malaysia and the other from France met and discussed the design of the collaboration through Skype. Each instructor chose one English course offered at their institutions and designed four tasks that could fit the syllabus of these two courses. The first task included video conferencing between one Malaysian student and one French student. The video conferencing served as an ice-breaking for the students to get to know each other and to obtain required information to understand their partners' country. This activity provided them with the opportunity to see who their partners were and to be familiar with their partners.

The second task was describing words and pictures associated with their country. Two Google documents were set up for the word and picture association task respectively. The participants were required to post a question on any word or picture related to the other country on the Google document. In other words, the Malaysian students would post questions on a word or picture related to France while the French students would post questions on a word or picture related to Malaysia. This task was open to all the participants whereby they did not only respond to their partners' entries or questions but also to other participants'. 
For the third task, the participants were divided into groups of four which consisted of two Malaysian students and two French students. Each group was required to produce a video. The video would contain information about their partners' country based on the themes listed. Google documents were set up for the participants to write their discussions and structure the storyline of their video. The purpose of this Google document was to monitor the participants' progress and ensure that there was no overlapping of titles. The video production was uploaded to YouTube and the link was shared with the students in Malaysia as well as in France. Upon completion of the video project, the participants viewed each video, wrote feedbacks about the videos and their reflections on the video production project. The feedbacks were written on a Google document set up for this purpose.

\subsection{Data Collection and Data Analysis}

The project was conducted over a period of twelve weeks. The data presented for this paper were from the semi-structured focus group interviews conducted on the Malaysian participants. The interview sessions were conducted upon the completion of the project. The participants were divided into three groups and each interview session lasted for one hour. The interview data were transcribed and analysed using thematic analysis.

\section{Findings and Discussion}

The findings generated from the interview data have highlighted important elements in language learning through e-collaboration between students of different regions. These elements are discussed in the next few sections.

\section{Language learning beyond the borders}

The findings indicated that there was evidence of language learning anxiety among the participants prior to the commencement of the project.

"I can talk in English to people that I (have not met before). To me it is a big thing. I (have) never talk(ed) in English (with people I don't know before)." [S2IntT1]

In this excerpt, it could be seen that the participant used to speak English only with people that she was familiar with. The online communication with someone of different cultural background from another country shifted her out of her comfort zone.

"Before this, I (have) never talk(ed) with foreigners from other countries. But when I (participated in) this project, I can interact with people from another country. It was a great experience for me." [S4IntT2]

Both the excerpts above show evidence that communicating online can help to increase language learners' confidence and reduce language learning anxieties. This finding is similar to the study conducted by Melchor-Couto (2016) who found that online communication increased language learners' self-confidence and reduced nervousness in foreign language learning, as learners became familiar with their interlocutors. 
Most of the participants did not have any experience communicating with people from other countries. Communicating online with someone from another country brought out a sense of excitement and increased the participants' motivation to use English as their medium of interaction.

\section{“...I don't think (the interactions) help (to improve my English)...I mean not really...(but) I actually develop(ed) somewhat different communication skills (from the one I had learnt)...I actually talk(ed) to a foreigner and via Skype...it's very new to me." [S9IntT2]}

Based on the above excerpt, the participant has learnt and developed two new skills. Firstly, intercultural communication skill, and secondly, communicating online.

The above findings suggest that e-collaboration provided a platform for the participant to activate his communicative resources (Choi \& Nunan, 2017). According to Choi and Nunan (2017) language learners activate their communicative resources when they need to communicate beyond their language classrooms and in an authentic context. In the case of this study, the participants did not only need to communicate in English outside the classroom, but also with an individual from another country where English was the only language that could connect them. In addition, the participants communicated with their partners through online platforms such as WhatsApp, email, Google document and Skype. The use of these platforms, particularly Skype, required them to learn and develop skills, not only about how to use the computer but also about how to communicate with someone in another country using electronic devices which is termed as electronic literacy (Shetzer \& Warschauer, 2000).

One of the participants indicated that he did not have many opportunities to use English in his daily life due to the local environment where Malay is the most commonly used medium of interaction.

"Although they (the French partner) are not native speakers of English, it is still a good opportunity for me to practise using the language because I don't have much chance...because we use more Malay in our (daily) communication." [S11IntT3]

In a country where English is a second language such as Malaysia, resorting to speakers' first language in their daily communication is a common practice (Ting, Then, \& Ong, 2018). In this case, the participant was a Chinese but interacted in Malay with his classmates as they were mostly Malays. In addition, it is also common for speakers to code-switch their first language and English when there are attempts to communicate in English (Maros, Noorizan, \& Zakaria, 2016).

"I need to practise (speaking) outside my comfort zone with other people from another country...with my friend, when I speak with them, I speak 
"rojak" (mixture of English and Malay)...but with (my partner) I need to speak fully in English." [S8IntT2]

According to Al-Sharaeai (2012), speakers often resort to their first language because they want to feel connected to their culture and when they could not find equivalent words to represent their intended meaning.

In addition, code-switching also occurs because speakers want to provide clarity to the message conveyed (Ting et al., 2018). In [S8IntT2], the fact that the participant's partner only spoke English and French, while he spoke English and Malay, did not allow him to practice code-switching. Thus, he had to learn to speak in English without code-switching. Language background of an interlocutor plays an important role in determining whether a speaker would code-switch or otherwise. In this case, if the participant knows French, codeswitching may still occur.

The findings discussed in this section highlights that students' language learning anxiety reduced, and their confidence level increased through ecollaborative learning with students of a different region. In addition, the approach limits the participants' opportunity to resort to their first language or code-switch and they had no choice but to learn to interact fully in English.

\subsection{Positioning the Role of the Partner}

The way the participants perceived the role of their partners seemed to give a significant impact in the way they positioned their collaborative language learning. In this study, the Malaysian participants acknowledged that English was not the first language of their French partners.

"...they are just like us...although we are not native speakers of English, we (are) actually learn(ing) together to complete the project...we (both) try to improve or English language skills together." [S1IntT1]

The participant acknowledged that both she and her partner were second or foreign language learners of English and the collaboration was a process for them to learn the language together.

"... feel that we (my partner and I) are both (not excellent) in terms of speaking because we are both learning English as a foreign language...it is a good opportunity for us to speak up and (we) do not hesitate to speak because we don't feel small..." [S11IntT3(1)]

In [S11IntT3(1)], the participant did not seem to worry about making mistakes and felt relaxed because his proficiency level and his partner's was similar.

"Our partner..they are not good in English. So, their (proficiency) level is the same as us. So they would understand what we talk (about). So if we learn from native speakers, sometimes we do not get what they say." [S2IntT1] 
In the excerpt above [S2IntT1], the participant seemed to suggest that language learners with limited proficiency produced similar language structure that would enable them to understand each other. Whereas, native speakers produced complex sentences which were difficult to understand.

The excerpts above show that the participants had developed a sense of confidence and were motivated to use English as a medium of interaction, and in learning the language. They also demonstrated evidence of independent learning where both parties work together to improve their English. This suggests the concept of peer learning where both groups of second/foreign language learners support each other and take charge of their learning.

"I think (if my partner is a native speaker), I will have another way of thinking because they are the native speakers of English. I will look up to them ..I would do more preparations before meeting my partner..." [S11IntT3(2)]

Within this context, the participant demonstrated a sense of pressure where he seemed to worry about making mistakes in communicating in English. Apart from that, the participant indicated that he would change the way he perceived his partner. His partner would be positioned as a mentor whereby he was superior and had control on the knowledge of the language. This change of role would make the participant dependent on his partner to guide him in terms of knowledge of the language. Thus, he may not have the sense of comfort in language learning as in peer learning as in [S11IntT3(2)] above which may reduce his confidence.

The findings shown in this section highlight the impact of positioning the role of a partner in e-collaborative learning. When a second or foreign language learner is paired with a native speaker of the target language, the partner is positioned as a mentor and the learner may become a dependent learner and may lack confidence in his or her language learning. On the other hand, when a second or foreign language learner is paired with a non-native speaker of the target language, the partner is positioned as a peer who is also learning. This position makes the learner more confident and independent in his or her language learning.

\subsection{Language Learning for Intercultural Communication}

The analysis of the interview data generated evidence that intercultural communication can improve English language learners' language proficiency.

\section{“...I feel like my English (has improved) a little bit...I get new experience meeting a foreign friend...it is actually my first time meeting a foreigner." [S1IntT1(1)]}

The participant demonstrated a sense of confidence and believed that the interactions with her partner had improved her proficiency. This finding is similar to a study by Sarwari and Wahab (2018) who investigated the relationship between English language proficiency and intercultural 
communication competence. In their study, it was found that English language learners' daily interactions with people of various cultural backgrounds helped them to gain confidence in language learning and improve their English language proficiency.

The current study has also highlighted the way in which language for intercultural communication is conseptualised. One of the participants had raised an interesting view about language when communicating with her partner.

"...when we convey messages to people, we should (make sure) that they understand (the message)...the language is actually for conveying messages in a correct way so that the message is understood." [S5IntT2(1)]

Based on the above excerpt, it could be concluded that the participant perceived language as a tool to convey messages. The most important aspect of communication is not about the accuracy of the language but the accuracy of the message conveyed.

Although the above findings show positive impacts on students' language learning, intercultural communication may also lead to a communication failure. Language learners who have not encountered with people of different cultural background may experience culture shock which could lead to language learning anxiety and impede language learning.

"...I think it was quite interesting. I (experienced) a bit of culture shock when I first wanted to interact with them because he (my partner) is a foreigner from another country...I gained a lot of knowledge...it's a great idea to continue this project." [S6IntT2]

According to Goldstein and Keller (2015), language learners with limited travel experience and ability to tolerate cultural differences often experience culture shock. In this case, the participant had not had any initial contact with any individual who was not a Malaysian, causing him to experience culture shock. However, with guidance from the instructor and discussions with his fellow classmates, he was able to overcome this issue. Preparing students with knowledge about cultural differences that might exist between them and their foreign interlocutors may help in reducing culture shock that the learners may experience.

Malaysian youths are known for their preference in using abbreviations. This can be found in a study conducted by Mokhsin et al. (2016) which investigated the use of abbreviations among youths in social networking. In the context of this study, evidence of using abbreviations among the participants can be observed in the excerpt below. 
"There was a time when I communicated with him, I used short forms, like "tba" (to be announced), and he was like, "what is that?" So, later, I have to type the words or sentences in full." [S5IntT2(2)]

This situation gave another perspective of using abbreviations to the participant where he realised that he would need to write complete sentences or words when communicating with people of different cultural background.

Based on the findings, it could be said that this project had provided a platform for the participants to learn about the culture of people from another country without having to travel.

"...(when we join this project) we can learn (about) their culture..". [S2IntT1(1)]

The project also gave opportunities to the participants to learn about their own country which they were not aware of before.

"Sometimes, there are things that we don't even know about Malaysia. But because they ask us about Malaysia, we must do research and be ready to give them information about Malaysia." [S2IntT1(2)]

In addition, they had the opportunity to learn how people from other countries may view their country.

"...(we know) what their perspectives are about Islam...So we can learn to be open-minded when we talk to (non-muslims) who are from another country." [S2IntT1(3)]

"This is actually my first experience to actually communicate with people from a different country and different religion...he shared many things with me...I can understand the lifestyle of people in France..." [S7IntT2]

The findings also showed that the participants had developed awareness about cultural differences.

"But we need to take care of our manners. We don't speak ridiculously..." [S1IntT1(2)]

Based on the above excerpt, it could be seen that awareness about cultural differences may influence the way the participants communicate with their partners. This finding coincides with the finding in a study conducted by Angelova and Zhao (2014) who investigated collaborative learning between American and Chinese students. The researchers found that the way their participants communicated with each other was dependant on their crosscultural awareness. 
Kim (2017) proposes that the strategies people of different cultural background use to communicate are affected by five conversational constraints. These strategies include considerations for other people's feelings, minimising imposition, avoiding negative evaluation by the hearer, concerns for clarity and effectiveness.

In [S2IntT1(1)] and [S2IntT1(2)] the participant seemed to be concerned about obtaining clarity about the culture of her partner and providing information about Malaysia to her partner. In [S2IntT1(3)], the participant seemed to expect that her partner could have negative ideas about her religion while in [S7IntT2], the participant was aware that she and her partner came from a different cultural and religious background, leading to different lifestyles. In both instances, the participants seemed to use the strategy of minimising imposition. In [S1IntT1(2)], awareness about cultural differences led the participant to be concerned about her partner's feelings. Therefore, she indicated that she was careful with the way she communicated with her partner.

"My partner asked about polygamy. I was like "Can I talk about this? Can I give you the answer to your question" (Then) I thought it is okay to share because you are not in my country. If you don't know the whole story you can't simply think badly about it." [S9IntT2]

In the above excerpt, the participant demonstrated a process of selecting the communicative strategy suitable to address the question. In the first part of the excerpt, the participant seemed to be concerned about his partner's evaluation on the issue of polygamy, thus suggesting that she was going to avoid explaining, perhaps since she was a female. However, in the second part of the excerpt, the participant felt that she needed to clarify the situation so that her partner would not have a negative evaluation of the issue of polygamy.

In intercultural communication, the communicative strategies used by a speaker are affected by his or her cultural background. Apart from that, awareness of cultural differences may also play an important role in influencing the communicative strategies used. In addition, a speaker goes through a process of analysing the communicative strategy that he or she should use in a particular context. At times, the strategy used may conflict the normal strategy that he or she would use to ensure that accurate information is provided to his or her interlocutors.

\subsection{Challenges in E-Collaborative Learning}

The main challenge in e-collaborative learning is having good connectivity. In this project, the participants were required to conduct video conferencing using Skype with their partners every week. The purpose of Skyping was not only to get the participants to know their partners but also to discuss their video production.

"Previously, I didn't have (internet connection) at home. So it was a big problem for me to have a video conferencing (at that time)." [S11IntT3]. 
In general, most of the students connect online using the university Wi-Fi. In the case of [S11IntT3] above, the participant lived in a hostel located on campus. Therefore, he did not have any problem conducting video conferencing during the semester. However, when he returned to his hometown for mid-term break, he did not have connectivity. As a result, he had to delay his video conferencing until he returned to his hostel the week after.

In addition to the availability of an internet connection, the connectivity must also be strong.

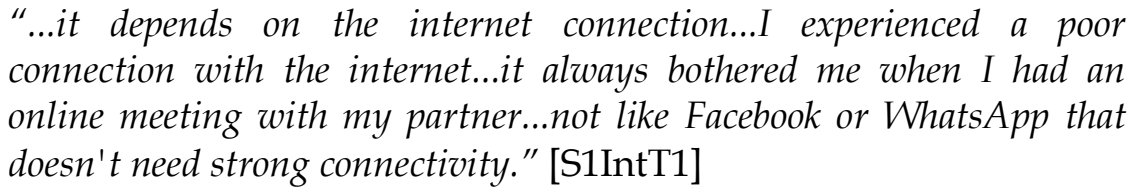

Poor connectivity could affect the participant's focus and enthusiasm on the task that she needed to perform with her partner. In a study conducted by Terhune (2016), it was found that poor internet connectivity prevented students from focusing on online face-to-face communication, leading to frustration in learning.

Apart from poor internet connectivity, different time zones could also lead to frustration in learning. There was a time difference between Malaysia and France where Malaysia is seven hours ahead of France.

"The timing is quite difficult. Sometimes he was available but I was not and sometimes I was available but he was not...It was difficult to have face-to-face interactions." [S3IntT2]

"When we set a particular time, sometimes things happened and we cannot be online." [S5IntT2]

This finding is similar to a study that investigated students' perceptions of using augmented and virtual reality in learning (Frydenberg \& Andone, 2018). The study involved university students in Romania and the United States and it highlighted that the differences in time zones caused frustration in learning.

In the context of this study, the proficiency levels of the Malaysian students were similar to that of the French students. In general, they were all keen on participating in the collaboration. However, there is a need to consider the design of collaboration when the class consists of students of a range of proficiency levels. Students with limited proficiency level may not contribute to the collaborative work while students with high proficiency level may feel burdened that they had to guide the low performers. This can be observed in a study conducted by Chang and Hannafin (2015). In their study, they found that low performers preferred to either do their own thing or wait for the high performers to give them the information needed to complete a task. As for the high performers, they felt irritated when they had to supply the knowledge to perform a task. 
Although conducting e-collaborative learning has positive impacts on language learning, the findings also highlighted challenges in implementing this approach. These challenges include poor internet connectivity and differences in time zones. These challenges may lead to failure and frustration in learning if not properly addressed. In addition, mixing students of various proficiency levels in a group to perform a collaborative task may also lead to frustration and failure in collaborative learning.

\section{Conclusion}

This study has highlighted the positive impacts of e-collaborative learning between students of different regions. The idea of communicating with people from another country who have similar proficiency levels as the participants helps to reduce language anxiety and increase confidence in using English as the medium of interaction. In this study, the French students are non-native speakers of English. With this status, the participants have viewed their collaborators as peers who are also learning English. This positioning plays an important role in collaborative learning. In addition, communicating with people from another country who speak English and other languages limits the opportunity to code-switch. An interesting conceptualisation that is raised in this study is that communicating in English is not about the accuracy of the language, but about the accuracy of the message conveyed to people of another country with different cultural backgrounds. From the theoretical perspective of online communication that involves people of different regions, cultural differences may impact on the success or failure of online communication (Reeder, Macfadyen, Roche, \& Chase, 2004). In addition, electronic literacy that includes the use of electronic devices to perform online communication, find information and perform online tasks also play an important role (Shetzer \& Warschauer, 2000). Thus, English language instructors who plan to conduct ecollaborative learning with students of another country should raise students' awareness about cultural differences and ensure that they have sufficient electronic literacy to avoid frustration in learning.

This study has provided knowledge and understanding about the impacts of ecollaborative learning between non-native learners of English between two regions based on students' reflection. Further investigation is needed to examine the impacts of e-collaborative learning and peer learning in terms of students' English language performance and communicative abilities.

\section{Acknowledgement}

This research is funded by Research Management Centre, Universiti Tun Hussein Onn Malaysia under TIER 1 grant, H092 project. 


\section{References}

Al Sharaeai, W. A. A. (2012). Students' perspectives on the use of L1 in English classrooms. (Master Dissertation), Iowa State University, Ames, Iowa.

Angelova, M., \& Zhao, Y. (2016). Using an online collaborative project between American and Chinese students to develop ESL teaching skills, cross-cultural awareness and language skills. Computer Assisted Language Learning, 29(1), 167185. https:// doi.org/10.1080/09588221.2014.907320

Chang, Y. J., \& Hannafin, M. J. (2015). The uses (misuses) of collaborative distance education technologies: Implications for the debate in transcience and technology. The Quarterly Review of Distance Education, 16(2), 77-92.

Choi, J., \& Nunan, D. (2018). Language learning and activation in and beyond the classroom. Australian Journal of Applied Linguistics, 1(2), 49-63. https://doi.org/10.29140/ajal.v1n2.34

Daniels, S. E., \& Walker, G. B. (2001). Working through environmental conflict: The collaborative learning approach. Wetport, C.T.: Praeger.

Froyd, J., \& Simpson, N. (2008). Student-centred learning: Addressing faculty question about student-centred learning. Paper presented at the The Course, Curriculum, Labor and Improvement Conference, Washington, D.C.

Frydenberg, M., \& Andone, D. (2018). Enhancing and transforming global learning communities with augmented reality. Journal of Information Systems Education, 29(1), 37-44.

Goldstein, S. B., \& Keller, S. R. (2015). U.S. college students' lay theories of culture shock. International Journal of Intercultural Relations, 47, 187-194. https:// doi.org/10.1016/j.ijintrel.2015.05.010

Kissau, S.P., \& King, E.T. (2014). Peer mentoring second language teaching: A mutually beneficial experience? Foreign Language Annals, 48(1), 143-160. https:// doi.org/10.1111/flan.12121

Kim, M. S. (2017). Cultural-based conversational constraints theory. The International Encyclopedia of Intercultural Communication (pp. 1-10). https://doi.org/10.1002/9781118783665.ieicc0102

Maros, M., Noorizan, N. D. M. M., \& Zakaria, A. H. I. (2016). Code switching as the medium of solidarity in 'Ola Bola'. Jurnal Komunikasi, 32(2), 1-28. https:// doi.org/10.17576/jkmjc-2016-3202-01

Melchor-Couto, S. (2016). Foreign language anxiety levels in second life oral interaction. ReCALL, 29(1), 99-119. https://doi.org/10.1017/S0958344016000185

Mokhsin, M., Aziz, A. A., Hamidi, S. R., Lokman, A. M., \& Halim, H. A. (2016). Impact of using abbreviation and homophone words in social networking amongst malaysian youth. Advanced Science Letters, 22(5-6), 1260-1264. https://doi.org/10.1166/asl.2016.6674

Okomoto, T. (2003, 9-11 July 2003). E-collaborative learning technologies and e-pedagogy Paper presented at the The 3rd IEEE International Conference on Advanced Technologies, Athens, Greece. https://doi.org/10.1109/icalt.2003.1215221

Reeder, K., Macfadyen, L. P., Roche, J., \& Chase, M. (2004). Negotiating cultures in cyberspace: Participation patterns and problematics. Language Learning and Technology, 8(2), 88-105.

Richards, J. C. (2015). The changing face of language learning: Learning beyond the classroom. RELC Journal, 46(1), 5-22. https:/ / doi.org/10.1177/0033688214561621

Sarwari, A. Q., \& Wahad, M. N. A. (2018). A study on the relationship between English language proficiency and intercultural communication competence among Arab students in Malaysia. Arab World English Journal, 9(1), 419-432.

https://doi.org/10.24093/awej/vol9no1.29 
Shetzer, H., \& Warschauer, M. (2000). An electric literacy approach to network-based language teaching. In M. Warschauer \& R. Kern (Eds.), Network-based Language Teaching: Concepts and Practice (pp. 171-185). New York: Cambridge University Press. https://doi.org/10.1017/cbo9781139524735.010

Tanghe, S., \& Park, G. (2016). "Build[ing] something which alone we could not have done": International collaborative teaching and learning in language teacher education. System, 57, 1-13. https://doi.org/10.1016/j.system.2016.01.002

Terhune, N. M. (2016). Language learning going global: linking teachers and learners via commercial Skype-based CMC. Computer Assisted Language Learning, 29(6), 10711089. https:// doi.org/10.1080/09588221.2015.1061020

Ting, S.-H., Then, D. C.-O., \& Ong, O.-B. (2018). Prestige of products and code-switching in retail encounters. International Journal of Multilingualism. https:// doi.org/10.1080/14790718.2018.1559321

Vygotsky, L. (1978). Mind in society: The development of higher psychological process. Cambridge, MA: Harvard University Press.

\section{Appendix}

\section{Interview Questions}

1. How do you feel about this collaboration?

2. What do you think about having to work with people from another region, not Malaysians?

3. What do you feel about having to work online?

4. Do you have any comments or recommendations to make it more interesting?

5. What do you think about the time difference?

6. What do you think about learning English with a non-native speaker of English? 